

\section{RANDALL STEVENSON. Reading the Times: Temporality and History in Twentieth-}

Century Fiction. Pp. ix+262. Edinburgh: Edinburgh University Press, 2018. Hardback, $£ 75$.

In Virginia Woolf's Orlando (1928), the narrator ponders the 'extraordinary discrepancy between time on the clock and time in the mind', and considers that it 'deserves fuller investigation'. In Reading the Times: Temporality and History in Twentieth-Century Fiction, Randall Stevenson undertakes just this task.

On Stevenson's account, an increasingly homogenous public time emerged in the nineteenth and twentieth centuries with the institution of a nationwide 'Railway Time' to replace local time zones; the codification of world standard time (centered on Greenwich) at the Prime Meridian Conference in Washington in 1884; and the implementation of Fordist modes of production in which labour was made efficient according to the rigours of Frederick Taylor's time and motion studies. Against the emergence of such a public time- — which can be allied with Orlando's 'time on the clock' - he argues that literature affirmed varieties of private time or 'time in the mind' (p. 19). Analysed using Gérard Genette's narratological terms, novels are seen as particularly adept at rendering complex forms of subjective temporal experience. For Stevenson, periods of particular historical stress - such as the First and Second World Wars, or the Cold War with its threat of nuclear destruction-witness the proliferation of temporally-experimental novels, abounding in narrative anachronies, repetitions, and ellipses. Drawing on Fredric Jameson's The Political Unconscious (1981), he contends that such literary experiments with time afford 'Utopian compensation' for the depredations of public time and modernity more generally (p. 25). 
In making this argument, the study traces the fortunes of temporally-experimental fiction over the course of the twentieth-century. Two strong early chapters concentrate principally on single authors: Joseph Conrad and D.H. Lawrence. The first advances a reading of Lord Jim (1900) and The Secret Agent (1907) in the context of Conrad's struggle to pass his maritime Board of Trade examinations, which involved complex calculations regarding Greenwich's Mean Times and meridians. The second convincingly addresses The Rainbow (1915) and Women in Love (1920) in the context of industrialization in the Midlands and the timediscipline that was exemplified by the practice of 'clocking on' and 'clocking off' for work. Surveying with considerably more sympathy what Wyndham Lewis in Time and Western Man (1927) had diagnosed as a 'cult of time', the central chapter situates modernist explorations of time in a range of scientific, philosophical, and cultural contexts, beautifully illustrated by the example of a page from The Times newspaper from November 1919, which both announced the first two-minute silence to commemorate Armistice Day, and proclaimed the 'Revolution in Science' brought about by Albert Einstein's Relativity theories (p. 93). The remaining chapters chart a movement away from hostility to clock-time in fiction: the 1930s witnessed an interest in longer time spans, including geological and cosmological spans of time, and postmodernism saw a turn to 'specular time', or the desire of fiction selfreflexively to explore its ability to manipulate temporal order. Although these chapters complicate the distinction between clock-time and private time, they never completely displace it. Indeed, in a perhaps surprisingly unhistorical claim, Stevenson suggests that conflict between the two forms of time 'may be inherent, or perennial, within consciousness itself, perhaps even reflecting biases within different hemispheres of the brain' (p. 235).

While it has great explanatory power, the guiding distinction of Stevenson's study-between public and private time - also has limitations. Certainly, there is a long precedent to thinking 
about time in modernism in similar terms, as the distinction in Orlando indicates. More recently, Stephen Kern's The Culture of Time and Space: 1880-1918 (1983) articulated the distinction in a highly influential manner. Yet the distinction has also been criticized. For example, in The Cosmic Time of Empire: Modern Britain and World Literature (2010), Adam Barrows has sought to displace it by resituating modernist experiments with time in the context of the tension between national and global time, which he draws from a revisionist reading of the 1884 Prime Meridian Conference. In part, the distinction is problematic because it tends to reduce the many different forms of time and temporality in the modernist novel to a homogenous exploration of individually-experienced 'private time'; in particular, it thereby risks occluding the communal and historical aspects of modernist temporality. Indeed, as Stevenson himself points out, it is curiously unable to elucidate what is most interesting about the experiment with time in Orlando, in which the central character lives through centuries and changes sex (p. 123).

Further, it might be regretted that the study does not take a more innovative approach to literary history. Stevenson's choice to concentrate predominantly on novels published in Britain is consistent with his diffusionist account of modernity, in which '[p]ressures exercised . . . by advancing technology and industrialisation — by modernity generally—were long experienced fairly exclusively within the industrialised nations of the West' (viii). However, alternative accounts of literary history might have been possible if, for example, the Caribbean plantation had been identified as a site of modernity, with its own distinctive history of time-discipline. Of course, the twentieth-century 'culture of time and space' that this study addresses contains many resources for rethinking new conceptions of literary history. For example, Ernst Bloch's notion of the 'simultaneity of the non-simultaneous' is currently being used by the Warwick Research Collective to explore a conception of world 
literature that is read alongside a history of modernity as one of combined and uneven development.

However, to raise these points is not to detract from the significant achievements of Reading the Times. Two of the great strengths of the study are that it relates temporal experiments in fiction to a wide range of material historical conditions, and that it identifies a large number of temporally-innovative novels, which span an entire century and are taken not just from Britain but also from France, the United States and other parts of the world. The impressively wide scope of the study is facilitated by Stevenson's great talents as a storyteller. Not only is Reading the Times a study of narrative, but it also deploys narrative in a highly skilful manner itself. For example, manipulating duration through light-footed summary, in which the innovations of a given novel are outlined in just one or two sentences, Stevenson is able to guide the reader effortlessly through vast tracts of literary history. Again, in a breathtaking analepsis, he takes the reader back from the twentieth century to trace the distinction between clock-time and time in the mind in the novels of Henry Fielding and Laurence Sterne, before finding hostility to time on the sundial in classical times expressed in The Boeotian Women, a play attributed to Plautus (pp. 230-5). By not confining himself to the restrictions that Orlando's biographer feels compelled to obey, and pursing the 'fuller investigation' that is tantalizingly mentioned, Stevenson is able to produce a rich and enjoyable narrative of fiction's various experiments with time over the course of the twentieth century. 